\title{
РАЗВИТИЕ РУССКОЙ МЕДИЦИНСКОЙ ТЕРМИНОЛОГИИ
}

\author{
The History of Russian Medical Terminology
}

Keywords: language, Latin, Greek, terms, Medical, History, modern, develope

Contact: Ostravská univerzita; angelikabogoczova@gmail.com

\begin{abstract}
«...удачные термины могут способствовать развитию науки, а неудачные тормозить развитие научных данных...»

(Гринев-Гриневич 1993: 9)
\end{abstract}

\section{Введение}

Настоящая статья посвящена краткой истории развития российской медицинской терминологии. Данная терминологическая база основана на двух основных словообразовательных системах. Известно, что медицинская терминология несет в себе древние исконно русские и интернациональные корни. Уникальность медицинской терминологии заключается в том, что она как единственная на свете реанимирует мертвый язык.

Невозможно унифицировать медицинскую терминологию в целом, поэтому, данная наука была, есть и будет самой сложной областью для лингвистического исследования. Медицинская терминология это и отголосок прошлого, и мост в настоящее. Сложилось так, что огромная терминологическая база данных оставалась без изменений несмотря на то, что наука как таковая, непрерывно развивалась. Вышеупомянутый факт является неким ключом к разгадке тайны развития медицинской терминологии. Почему область науки, которая так стремительно меняется и развивается использует ту же самую терминологическую базу на протяжении многих веков? С какой стороны подойти к исследованию медицинской терминологии для того, чтобы ее объективно описать. Поможет ли раскрыть сущность терминообразовательного аппарата изучение исторического аспекта, или же напротив свет внесет действительность XXI века, порог которого мы не так давно перешагнули. 
Цель каждого лингвиста - это знание и понимание системы языка, как бы банально это не звучало. Принято думать, что все живое и неживое имеет начало. Для объективного взгляда на медицинскую терминологию неоспоримо необходимы знания истории происхождения данной терминосистемы. Но даже письменные памятники, на которые мы опираемся, к сожалению, не всегда нам открывают всю суть для точного осмысления. С каждым отрезком времени выплывают на поверхность все новые и новые доказательства теорий и домыслов. Этимологическое исследование служит для выявления закономерности развития медицинской лексики. Не всегда путь изучения и рассмотрения источников является единственным. Медицинская терминология имеет много общего с медициной как таковой. Если мы не знаем историю болезни пациента, приходится подождать аутопсию умершего, которая, между словом, откроет о жизни человека и его быту намного больше, чем вся возможная исчерпывающая информация в течение жизни. В русле данной метафоры, терминология также подлежит вскрытию, без которого «здоровье», «болезни» и «недостатки» терминосистемы невозможно раскрыть. Стоять перед трупом и задавать телу вопросы недостаточно. Перед тем как сделать первый неглубокий надрез, необходимо провести осмотр. Что вообще из себя представляет данный слой научной терминологии, чем руководствуется и какие новые тенденции возможно уже вскоре определят направление и развития медицинской терминологии?

В настоящее время лингвистические работы, посвященные медицинской терминологии, унифицировали несколько групп, в которые термины можно распределить. Данные слои возникали постепенно, не только в русском, но и других языках. К основной группе относятся собственные наименования. Далее под влиянием греческого и латинского языков, возникают заимствования элементов слов и целых терминов. В течение многих веков именно благодаря греко-латинским элементам развивается медицинская лексика. Наш век приносит такую модернизацию, которую лексика мертвых языков не способна покрыть и язык возвращается к своим корням. Изобретения носителя языка сегодня нуждаются в наименовании носителя данного языка.

\section{Бытовая и заимствованная терминология}

К первой группе, как было уже сказано, относятся исконно русские наименования, которые благодаря летописям дошли до нас из глубины веков. Известно, что еще в древнерусском языке существовала первая медицинская терминологическая база. Медицинская лексика складывалась на основе народных наименований. 
Лексика, которую использовали «лечцы», (врачи и хирурги того времени, но также колдуны) несет оттенки и особенности былых времен. Исторические источники не всегда достоверны, а так возможно лишь с долей субъективности предполагать, что даже знахари того времени прибегали к определенному количеству заимствований. Так, например, «Повесть временных лет» упоминает знахаря сирийца.

Сравнивать медицинскую терминологию Древней Руси и современную терминологическую базу невозможно. Начиная язычеством и кончая христианством древние народы видели узкую связь между миром постороннего и миром живого. Сегодня мы уже научились отличать свою биологическую сущность от духовного влияния. Лечение в древние века не осуществлялось без заговоров, молитв и применения чудотворных зелий. Скорее речь шла о накопленном народном опыте и немногочисленных поверхностных знаний о анатомии человека. Так возможно предположить, что многие медицинские термины того времени были навсегда утрачены, а лишь небольшая их доля дошла до наших дней.

Как писал анатом И. Гиртль «(...) неудивительно, что в той части анатомии, которая дошла до нас с самой отдаленной древности, встречаются весьма странные, смешные названия, диаметрально противоположные известным ныне физиологическим отправлениям органов. Употребляемые медицинские названия своим значением совершенно противоречили тому, что о анатомии известно в наше время. Средние века были еще несчастнее в своем выборе анатомических терминов. Данный парадокс выражается в не подходящих названиях, мистический или религиозный смысл которых, может быть, служил к примирению анатомии с духом времени, весьма ей не благоприятствовавшим» (Гиртль 1874: 23).

Письменные памятники донесли до нашего времени такие исконно русские медицинские термины, как: бебехи (почки), блонка самоцветная (ирис, радужная оболочка глаза), выть (еда, голод, аппетит), глядельцее (зрачок), гусачина (диафрагма), духовая жила (трахея, дыхательное горло), крятание (жевание пищи), кутырь (желудок). В медицинских текстах встречались и ныне забытые термины, образованные от греческих слов: мелась (желчь, от греч. мелан); всемясная железа (поджелудочная железа, от греч. пан - общий, весь и креас мясо). О последнем термине напоминает современное слово панкреатит. Органы 
чувств называли многоразличныли разсудами, язык - брацалом глаголющим, шея предназначалась для того, чтобы уберечь голову от спадения от вертения. ${ }^{1}$

К общеславянскому пласту медицинской терминологии можно отнести термины: бельмо, бок, бровь, волос, воспа (оспа), голова, горло, грудь, грыжа, губа, зуб, лицо, лоб, моча, нос, ноготь, плод, почка, рак, рука, селезенка, сердче, темя, ухо и др. Можно считать древнерусскими слова, общие для церковнославянского и древнерусского языков, а также слова, принадлежавшие к одному из них, но устойчиво вошедшие в русский литературный язык, например: беременная, бесплодие, близнецы, болезнь, боль, больной, гной, голень, гортань, жажда, желудок, желчь, зачатие, здоровье, зрение, кишка, кожа, кость, лекарство, лечебный, лечение, лечить, мозг, мозоль, мышща, ноздря, обоняние, осязание, отек, отравление, пах, печень, плева, плечо, подошва, пояснища, пуп, рожа, рот, судорога, тело, челюсть, череп, шея, язва и др.» ${ }^{2}$

Как замечает Н. А. Богоявленский, большую роль в жизни всего живого играли кости, которые являлись весьма ценным материалом. Подтверждением чего являются термины: костарь (игрок в кости, зеренщик), костоправ (ортопед), костолом (дробильщик костей для выварки), костовар (изготовитель клея), костяник (мастер по грубой выделке кости), косторез (мастер «изящных ремесел») (Богоявленский 1970: 3).

С течением времени иностранные знахари приносят новые знания, а с ними и новую лексику. Так следующим широким пластом медицинских терминов является группа заимствованных слов. Несмотря на то, что русская лексика $\mathrm{X}$ XIII вв. уже пользуется заимствованиями, греческий язык в особенности начинает свое влияние с приходом христианства на Руси.

Так во всем мире происходит языковое смешение, разумеется, благодаря переводам медицинской литературы, а также, как известно, иностранным врачам, приносящим свой бесценный опыт. Постепенно наряду с бытовой лексикой существуют заимствованные термины синонимы, со временем искореняющие исходные наименования. Данное развитие не сильно затрагивает одну отрасль лексики, тесно связанную с «врачеваем», т. е. названия растений, которые с глубокой древности дошли до наших времен практически без изменений. Например, наименования: польнь, крапива, подорожник, листья березы, кора

\footnotetext{
${ }^{1}$ Сабурова, Ю. Т., Рахимова, 3. М., Тангриберганова, Г. О. История становления и развития русской медицинской терминологии. Молодой ученый. 2015 (89/9), с. 1407-1411. Режим доступа: https://moluch.ru/archive/89/17271/ (2020-04-20).

${ }^{2}$ Абдуллаева, М. Ж., Сабурова, Ю. Т., Рахимова, 3. М. Переводы заимствованных медицинских терминов. Молодой ученый. 2015 (88/8), с. 1084-1087. Режим доступа: https://moluch.ru/archive/88/17174/ (2020-0420).
} 
ясеня, чеснок, хрен, мед, прополис, жир медведя и т. д. не нуждаются в переводе или объяснении. ${ }^{3}$

XVIII-начало XIX вв. принято так или иначе связывать с формированием русского литературного языка. В язык еще в большей степени проникают терминоэлементы и термины греко-латинского происхождения. Еще до XVIII столетия любая существующая наука была достоянием немногих людей, которые могли пользоваться возвышенным, отрешенным от повседневности книжным языком ${ }^{4}$. В начале XVIII в. все начинает менятся, язык науки проникает практически до всех слоев населения. Благодаря тому, что верхние слои общества в своем общении широко используют заимствования, а в народе принято прибегать к лексике бытовой, возникает глубокая пропасть между исконно русским и новым русским языком медицины. Под давлением заимствований происходит варварское вмешательство в натуральное развитие языка. Данный аспект более всего затронул язык науки. В языке медицины часто элементы сразу нескольких языков заменяют более подходящую по отношению к реалиям бытовую лексику. Не смотря на некий хаос постепенно все же с течением времени происходит обработка, систематизация и унификация медицинской терминологии.

Невозможно не упомянуть значимую роль церковнославянского языка, так как именно он и был мостом, соединяющим новую терминологию, содержащую греко-латинские элементы и терминологию бытовую, уже существующую. Ученые монахи не только являлись отличными врачевателями, а также превосходно знали несколько языков, латынь и греческий. Именно данный факт в дальнейшем повлиял на то, что русская медицинская терминология начинает гармонично сливаться с греко-латинскими элементами. В это же время тенденция заимствований побуждает к написанию работ и двуязычных словарей. Медицинская наука XVIII в. складывалась практически параллельно как на Руси, так и в Европе.

Характерной особенностью того времени было двуязычие, при котором русский народный язык взаимодействовал с церковнославянским искусственным письменным языком, окончательно оформившимся в конце XVI в. Оба языка имели разные сферы применения: в устном общении пользовались

\footnotetext{
${ }^{3}$ Семенченко, В. Ф. История фармации: Учебное пособие. Москва: ИКЦ Март, 2003.

${ }^{4}$ Райнов, Т. Н. Наука в России XI-XVII веков. Москва: Издательство АН СССР, 1940.
} 
русским народным языком, его же использовали и в личных эпистоляриях; трактаты с научной и деловой тематикой писались на церковнославянском ${ }^{5}$.

Во второй половине XIX в. увеличивается влияние латинского и греческого языков, благодаря развитию образования в области медицины. Учителя лечебного дела внедряют новые формы и терминоэлементы из греческого и латинского языков. И здесь впервые зарождаются т. наз. искусственные термины, как например: лейкемия (слово из греко-латинских элементов, где leuc - белый, и аетіа - состояние крови (Кондратьев 2009). Данный период ознаменовался не былым интересом к медицинской терминологии, что вело к переосмыслению и уточнению медицинской лексики.

Весьма важным толчком для систематизации русской медицинской терминологии послужил вышедший в 1835 году «Врачебный словарь», составленный А. Н. Никитиным, учредителем и первым секретарем общества русских врачей Петербурга, первый в России медицинский словарь, в котором было дано толкование терминов.

Развитие медицинской терминологии XX века формирует основы для терминологической теории, благодаря таким ученым как Д. С. Лотте, Э. К. Дрезен, Е. Вюстер, Г. О. Винокур, А. А. Реформатский. Именно их труды на долгое время определили направление практической деятельности по стандартизации и интернационализации терминологии (Татаринов 1994). Также первая половина прошлого века бескомпромиссно вводит значительное количество заимствований. Несмотря на то, что медицинской терминологией попрежнему занимаются сами медики, такая дисциплина как теоретическое терминоведение, практически отсутствует. Научные исследования медицинской терминологической базы данных протекают в русле основоположников российской медицинской школы и скорее сосредотачиваются на словари и пособия по различным разделам медицины. Что же касается бытовой лексики, та постепенно под давлением греко-латинских заимствований, уходит на второй план.

Выделение и становление медицинского терминоведения как самостоятельной дисциплины происходит постепенно во второй половине XX века. Наблюдается осмысление необходимости лингвистического подхода к данной проблематике. Возникают первые ценные методические работы, которые дают понять, что возникшая пропасть в описании природы медицинской

\footnotetext{
5 Ларин, Н. Н. Лекции по истории русского литературного языка (X-середина XVIII в.). Москва: Высшая школа, 1975. 
терминологии может неотвратимо повредить хрупкий слой лингвистической ветки. Ученые уделяют большое внимание описанию и исследованиям специальной лексики. В последнее время возникает большое количество словарей. В вопросах этимологии прослеживается подробное изучение и анализ происхождения медицинских терминов.

Как объясняет С. В. Гринев-Гриневич, «во второй половине ХХ столетия в стране наблюдалось бурное развитие терминологических исследований, закончившихся в 1980-х гг. формированием терминоведения как самостоятельной комплексной научной дисциплины. Последующие годы ознаменовались появлением уже на базе терминоведения ряда самостоятельных терминоведческих дисциплин, что свидетельствует о постепенном превращении терминоведения из комплексной науки в комплекс взаимосвязанных научных дисциплин» (Гринев-Гриневич 2004: 23).

В течение 80-ых годов прошлого века научные лингвисты начинают сталкиваться с нарастающим дефицитом обновленной терминологической базе, которая отстает от быстрого развития науки и техники. Растут проблемы в области теоретической и практической медицины, которая нуждается в обновленной, унифицированной терминологической базе. Лексика должна обновляться, также, как и достижения медицины. Греко-латинские элементы, которые уже в современном мире медицины не подлежат модернизации все еще играют большую роль в пополнении медицинской терминологии. Лингвисты оценили систематизированное издание трехтомного «Энциклопедического словаря медицинских терминов» под ред. академика Б. В. Петровского (19821984). Словарь адресован врачам, ученым в области медицины, студентам медицинских учебных заведений, а также лингвистам. Около 60000 терминов описаны в 40206 статьях, большой интерес представляют собой дополнительные справочные материалы - исторический очерк о развитии медицинской терминологии и словарь греко-латинских терминоэлементов (этимологический справочник) (Петровский 1982-1984).

Последние десятилетия медицина, как известно, характеризуется быстрым рывком своего развития. «Процесс расширения знаний, становления новых направлений, а также исследований сопровождается возникновением интерференций, взаимовлияния и взаимопроникновения лексики смежных или взаимодействующих специальностей, что усилило терминологические трудности» (Бекишева 2007: 29). Поэтому, для исследования установления общих принципов унификации медицинской терминологии и выработки рекомендаций по выбору конкретных методов нормализации и стандартизации терминологий 
различных областей медицины, необходимо провести предварительное, достаточно точное системное описание отдельных блоков медицинской специальной лексики и происходящих в них терминологических процессов. Проводиться именно такая работа сотрудниками Научно-исследовательской лаборатории медицинской терминологии РАМН (Гринев-Гриневич 1993: 3).

\section{Заключение}

Конец XX и начало XXI веков - это непрерывная деятельность в области науки и техники. До сих пор еще никогда во всей истории человечества не происходило такого обширного смещения и вливания наук одной в другую. Все биологические процессы, жизнь и здоровье человека тесно связаны не только с медициной, но и с компьютерными технологиями, космонавтикой и виртуальной реальностью. Проникновение медицины в новые области науки ускоряют процесс развития терминологической базы. Именно это и заставляет ученых проводить активную лингвистическую деятельность. Мы наблюдаем, что конференции посвященные, в частности, проблемам, связанным с медицинской терминологией, несут как теоретический, практический, так и дидактический вклад. Такие конференции были организованы в России по инициативе и под руководством редакционной коллегии издательства «Медицинская энциклопедия», по инициативе членов Проблемной методической комиссии по латинскому языку и медицинской терминологии при Всероссийском учебно-научно-методическом центре по непрерывному медицинскому и фармацевтическому образованию (Москва, 1982 г.; Саратов, 1993 г.; Самара, 1998 г.; Москва, 2003 г. и т. д.). «Эти конференции дали возможность научного общения не только лингвистам, но и медикам, интересующимся вопросами терминологии, и показали эффективность и плодотворность сотрудничества специалистов гуманитарных и естественнонаучных областей знания на пути унификации терминологии и оптимизации учебного процесса в медицинских вузах» (Бекишева 2007: 32). Данная деятельность уже приносит свои плоды. Ученые признают, что решение конкретных вопросов и задач, в последствие, может помогать при создании и написании новых научных статей, учебных пособий по медицинской терминологии и специализированных словарей.

Интернет-источники нам предлагают ряд новаторских работ и исследований в области медицинской терминологии. Так невозможно не упомянуть, что в 2002 году возник «Медицинский энциклопедический словарь» под ред. В. И. Бородулина. Под ред. Л. Л. Колесникова в 2003 году была издана 
энциклопедия «Международная анатомическая терминология» на латинском, английском и русском языках.

Медицинская терминология не предусматривает многозначности, даже скорее возможно утверждать, что многозначность ей противопоказанна. Поэтому изучение и исследование медицинской терминологии нуждается в конкретном подходе. Данный слой терминологической базы, также как любой другой развивается на фоне социальных, культурных и ментальных особенностей эпохи. Именно медицинская лексика нуждается в непрерывной обработке.

\section{Summary}

Medical terminology is a set of words that serve not only medicine, but also our everyday life. These terms must be accurate and unambiguous. In the terminological system of medicine, a large place is occupied by the terms that came into the Russian language from Latin and Greek. In order to understand the nature of the language of medicine, it is necessary to study the historical development of this language. Despite the huge layer of borrowed words, home vocabulary also occupies a large place. Recently, we have observed that everyday life vocabulary also affects the development of the language. The question remains what exactly helps to strengthen certain terms.

\section{Литература}

Бекишева, Е. В. Современное состояние медицинского терминоведения. In: Федорина, Т. А. (еd.) Язык медицины: Всероссийский межвузовский сборник научных трудов. Самара: СГМУ, 2007.

Богоявленский, Н. А. Отечественная анатомия и физиология в далеком прошлом. Москва: Издательство Медицина, 1970.

Гиртль, И. Руководство $\kappa$ анатомии человеческого тела с указанием на физиологические основания и практические применения. Пер. с нем. П. Баллода и А. Даманцина, 1874.

Гринев-Гриневич, С. В. Введение в терминоведение. Москва: Издательство Московский лицей, 1993.

Гринев-Гриневич, С. В. О современном состоянии терминоведения (от комплексной науки - к комплексу научных дисциплин). In: ГриневГриневич, С. В. (ed.) Научно-техническая терминология. Выпуск I. Москва: Госстандарт: ВНИИКИ, 2004. 
Кондратьев, Д. К. (общ. ред.) Латинский язык. Анатомическая номенклатура, фармачевтическая терминология $u$ рецептура, клиническая терминология: учебно-методическое пособие для студентов лечебного, педиатрического, медико-психологического и медико-диагностического факультетов. Гродно: ГрГМУ, 2009.

Ларин, Н. Н. Лекичии по истории русского литературного языка (X-середина XVIII в.). Москва: Высшая школа, 1975.

Райнов, Т. Н. Наука в России XI-XVII веков. Москва: Издательство АН СССР, 1940.

Семенченко, В. Ф. История фармащии: Учебное пособие. Москва: ИКЦ Март, 2003.

Татаринов, В. А. История отечественного терминоведения. Москва: Московский лицей, 1994.

\section{Интернет-источники}

Абдуллаева, М. Ж., Сабурова, Ю. Т., Рахимова, 3. М. Переводы заимствованных медицинских терминов. Молодой ученый. 2015 (88/8), c. 1084-1087. Режим доступа: https://moluch.ru/archive/88/17174/ (2020-0420).

Петровский, Б. В. (гл. ред.) Энииклопедический словарь медицинских терминов. В 3-х томах. Москва: Советская энциклопедия, 1982-1984. Режим доступа: http://www.rubricon.com/about_dmt_1.asp (2020-04-20).

Сабурова, Ю. Т., Рахимова, З. М., Тангриберганова, Г. О. История становления и развития русской медицинской терминологии. Молодой ученый. 2015 (89/9), c. 1407-1411. Режим доступа: https://moluch.ru/archive/89/17271/ (2020-04-20).

Режим доступа: https://vitanova.ru/pdf/fz/lukretci/files/assets/basic-html/page17.html (2020-04-20). 